\title{
Treatment of Wastewater Using Reverse Osmosis for Irrigation Purposes
}

\author{
MhdAmmar Hafiz \\ mh1201889@qu.edu.qa \\ Department of Civil and Architectural Engineering, Qatar University, Doha, Qatar \\ Alaa H. Hawari \\ a.hawari@qu.edu.qa \\ Department of Civil and Architectural Engineering, Qatar University, Doha, Qatar \\ Radwan Alfahel \\ ra1404482@qu.edu.qa \\ Department of Civil and Architectural Engineering, Qatar University, Doha, Qatar
}

\begin{abstract}
This work investigates the performance of reverse osmosis (RO) for the reclamation of treated sewage effluent (TSE) to be used as irrigation water for food crops. The feed water used in this study was a real sample of ultra-filtered tertiary treated sewage effluent (TSE). Reverse osmosis (RO) was evaluated using the following experimental conditions; applied pressure (10 - 20) bar, flow rate 3.5 LPM and (BW30LE) membrane. The performance of RO was evaluated according to the water flux and rejection of dissolved solids. The final water quality was compared with irrigation water standards. The results reported in this study show that reverse osmosis (RO) is capable of reclaiming treated sewage effluent (TSE) to be used as irrigation water for food crops. The maximum average flux was 77.7 LMH achieved using a feed pressure of 16 bar. The permeate water generated using RO had high quality which met the irrigation standards for food crops.
\end{abstract}

Keywords: Irrigation water; Reverse osmosis; Wastewater treatment

\section{INTRODUCTION}

Water scarcity is one of the most challenging problems that affect agriculture worldwide, especially in arid areas. The United Nations estimate that agriculture accounts for $70 \%$ of water usage around the world (Hafiz et al., 2019). Treated wastewater is an economical solution to be used as irrigation water (Shanmuganathan et al., 2015). However, treated wastewater may damage the soil because of the excessive salts, pathogens, organics, sodium and chloride content. Shanmuganathan et al. (2015) studied the possibility of enhancing the quality of micro-filtered treated sewage effluent using nanofiltration (NF) and reverse osmosis (RO). The study showed that using NF and RO alone could not produce permeate which meets irrigation standards. However, irrigation suitable permeate was produced using a NF-RO hybrid system. In addition, it was found that utilizing NF before RO reduced the RO membrane fouling. Liu et al. (2011) evaluated the effectiveness of nanofiltration and reverse osmosis in the treatment of treated textile effluent in terms of salinity reduction and COD rejection (Liu et al., 2011). The results showed that nanofiltration exhibited more severe flux decline compared to reverse 
osmosis (RO) because of the higher porosity and membrane fouling of the nanofiltration membrane. RO showed higher total salts rejection compared to NF. The study evaluated the effect of operating pressure and feed solution $\mathrm{pH}$. The experimental results showed that optimum performance was achieved using a 12 bar pressure, $\mathrm{pH}=4$ and a flow rate of 8 LPM. Protein-like substances of high molecular weight (MW) are the dominant foulants on the membrane surface (Liu et al., 2011).

Several studies have been performed on the treatment of sewage effluent using reverse osmosis; however, none of the studies have evaluated the performance of reverse osmosis for the reclamation of ultra-filtered tertiary treated sewage effluent to be used in irrigation for food crops. The objective of this paper is to evaluate the feasibility of using reverse osmosis in reclaiming ultra-filtered tertiary treated sewage effluent to be used as irrigation water for food crops.

\section{MATERIALS AND SETUP}

Tertiary treated sewage effluent (TSE) was used as feed water to the reverse osmosis process. TSE was collected from a wastewater treatment plant located in Doha, Qatar. The characteristics of the collected treated sewage effluent are summarized in Table 1. The water quality was compared with FAO standards ( Lejalem et al., 2018; Parlar et al., 2019). TDS of tertiary treated TSE was $1461 \mathrm{ppm}$ which is almost two times higher than the allowable limit. The electrical conductivity was $2.56 \mathrm{mS} / \mathrm{cm}$ which is 3 times higher than the allowable limit. Figure 1 shows a schematic diagram for the experimental setup.

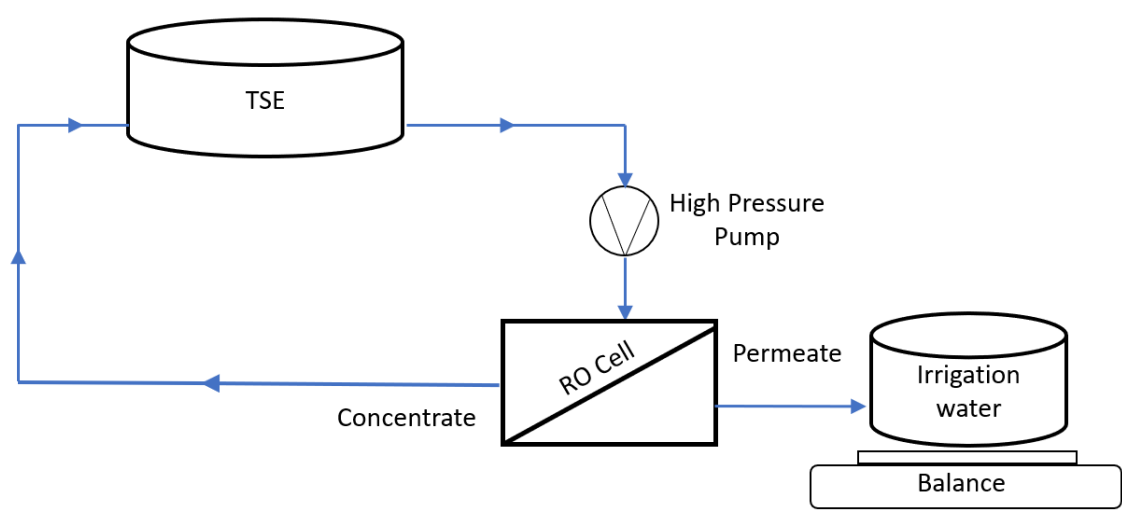

Figure 1: Schematic diagram of reverse osmosis lab scale test skid

Table 1: Characteristics of tertiary treated sewage effluent (feed water)

\begin{tabular}{|c|c|c|}
\hline Parameter & Value & Limit \\
\hline TDS (ppm) & $1461 \pm 5$ & 750 \\
\hline Turbidity (NTU) & $0.2 \pm 0.1$ & 2 \\
\hline EC (mS/cm) & $2.56 \pm 0.2$ & 0.7 \\
\hline
\end{tabular}




\section{RESULTS AND DISCUSSION}

The water flux $J_{w}$ was calculated using the following equation (Thabit et al., 2019):

$$
J_{w}=\left(\frac{V_{p}}{A_{m} \times t}\right)
$$

Here, $V_{p}$ is the volume of the permeate $(\mathrm{L}), A_{m}$ is the area of the membrane $\left(\mathrm{m}^{2}\right)$, $\mathrm{t}$ is the operating time (h). Figure 2 shows the average water flux using different feed pressure. In $\mathrm{RO}$, when the applied pressure was $10 \mathrm{bar}$, an average water flux of $21.3 \mathrm{LMH}$ was obtained. When the applied pressure increased to 12 bar the water flux increased by 3 times where the average water flux was 68.1 LMH. At a 14 bar applied pressure the water flux increased by 5\% compared to the water flux at 12 bar applied pressure where the average water flux was $71.5 \mathrm{LMH}$. At an applied pressure of 16 bar the average water flux increased to reach an average water flux of $77.7 \mathrm{LMH}$. As the applied pressure further increased the average water flux decreased. Where at an applied pressure of 18 bar and 20 bar the average water flux was 71.6 LMH and 67.5 LMH, respectively. The average water flux increased as the applied pressure increased until it reached a specific value. The maximum average water flux was obtained at an applied pressure of 16 bar. As the applied pressure increased more than 16 bar the average water flux started decreasing. The water permeability increases as the feed pressure increases; however, applying excessive pressure may result in accumulation of foulants on the membrane surface which results in lower average water flux (Jiang et al., 2017; Qasim et al., 2019).

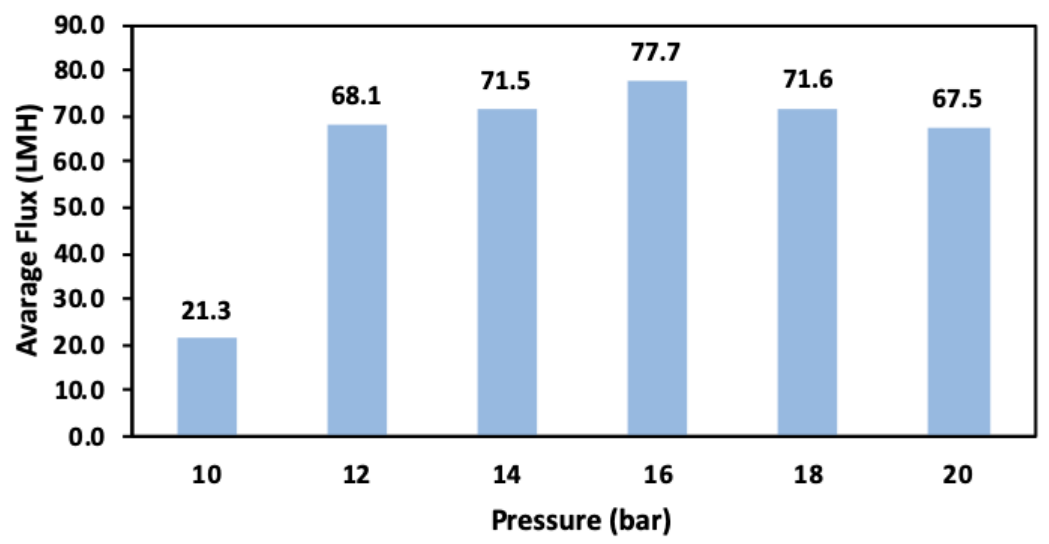

Figure 2: Average water flux using flow rate $=3.5 \mathrm{LMP}$ and different feed pressure

Figure 3 shows the total dissolved solids (TDS) concentration in the permeate water. According to Food and Agriculture Organization (FAO), the TDS of irrigation water should not exceed $750 \mathrm{ppm}$ (Ayres \& Westcot, 1985). The RO process was effective in reclaiming TSE using feed pressures between 10-20 bar, where the total dissolved solids was below the allowable limit. The applied pressure has minimal effect on the TDS of permeate water. However, at an applied pressure of 20 bar, TDS increased dramatically to $559 \mathrm{mg} / \mathrm{L}$. 


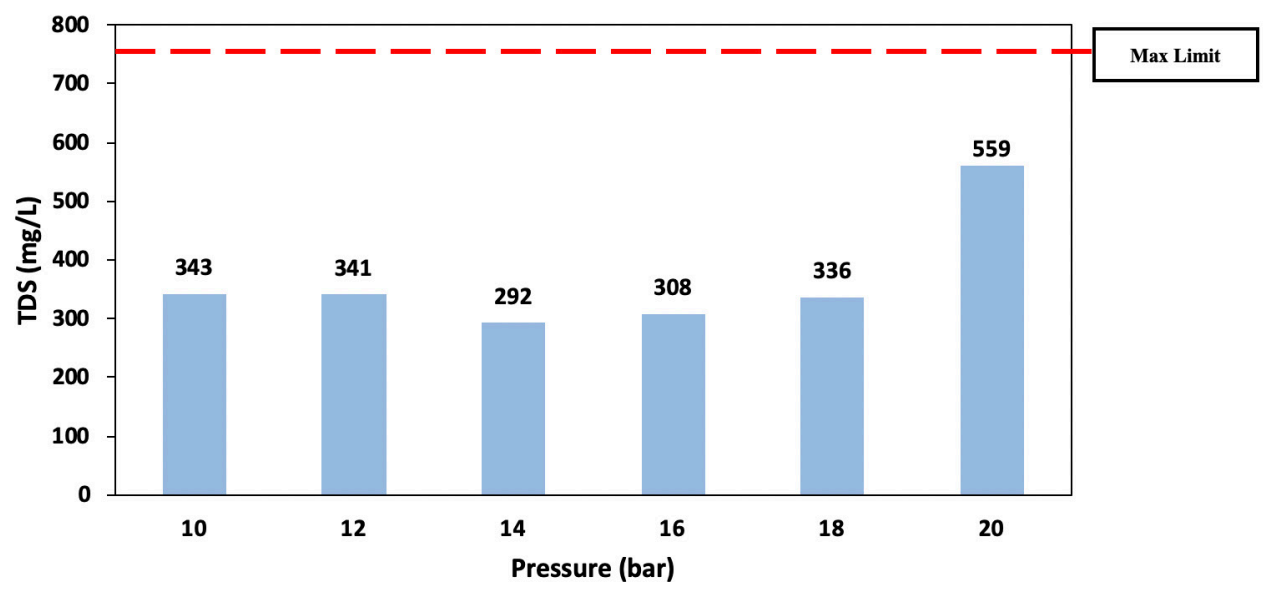

Figure 3: TDS of RO permeate using flow rate=3.5 LMP and different feed pressure

\section{CONCLUSION}

The results reported in this study show that reverse osmosis (RO) is capable of reclaiming treated sewage effluent (TSE) to be used as irrigation water for food crops. RO is suitable for the reclamation of wastewater because of the high rejection of dissolved ions, where the TDS of permeate water was within the allowable limits recommended by FAO. The most suitable and economical irrigation water was obtained using a feed pressure of 14 bar and flow rate of 3.5 LPM.

\section{ACKNOWLEDGMENTS}

This research is made possible by graduate sponsorship research award (GSRA6-10509-19021) from Qatar National Research Fund (QNRF). The statements made herein are solely the responsibility of the authors.

\section{REFERENCES}

Hafiz, M. A., Hawari, A. H. \& Altaee, A. (2019). A hybrid forward osmosis/reverse osmosis process for the supply of fertilizing solution from treated wastewater. Journal of Water Process Engineering, 32, 100975.

Jiang, S., Li, Y. \& Ladewig, B. P. (2017). A review of reverse osmosis membrane fouling and control strategies. Science of the Total Environment, 595, 567-583.

Lejalem, A., Dagnaw, B. C., Zewge, F. \& Ababa, A. (2018). Fluoride content of leafy vegetables, irrigation water, and farmland soil in the rift valley and in non-rift valley areas of Ethiopia. Fluoride, 50.

Liu, M., Lü, Z., Chen, Z., Yu, S. \& Gao, C. (2011). Comparison of reverse osmosis and nanofiltration membranes in the treatment of biologically treated textile effluent for water reuse. Desalination, 281, 372-378.

Parlar, I., Hacıfazlığlu, M., Kabay, N., Pek, T. Ö. \& Yüksel, M. (2019). Performance comparison of reverse osmosis (RO) with integrated nanofiltration (NF) and reverse osmosis process for desalination of MBR effluent. Journal of Water Process Engineering, 29, 100640. 
Qasim, M., Badrelzaman, M., Darwish, N. N., Darwish, N. A. \& Hilal, N. (2019). Reverse osmosis desalination: A state-of-the-art review. Desalination, 459, 59-104.

Shanmuganathan, S., Vigneswaran, S., Nguyen, T. V., Loganathan, P. \& Kandasamy, J. (2015). Use of nanofiltration and reverse osmosis in reclaiming micro-filtered biologically treated sewage effluent for irrigation. Desalination, 364, 119-125.

Thabit, M. S., Hawari, A. H., Ammar, M. H., Zaidi, S., Zaragoza, G. \& Altaee, A. (2019). Evaluation of forward osmosis as a pretreatment process for multi stage flash seawater desalination. Desalination, 461, 22-29. 